\title{
PENGEMBANGAN USAHA MIKRO JAMUR TIRAM PUTIH (STUDI KASUS : PEMBUATAN ALAT KONTROL SUHU, KELEMBABAN DAN PEMBUATAN WEBSITE PEMASARAN BENTENG HILIR-DELI SERDANG)
}

\author{
Ikhsan parinduri ${ }^{1 *}, \mathrm{~S}$ \\ ${ }^{1}$ Program Studi Sistem Komputer STMIK Royal Kisaran, \\ Email : Ikhsanparinduri9@gmail.com
}

\begin{abstract}
Has been Community Service for Micro-Business White Oyster Mushroom "Temperature control and humidity, Lower Fortress, Deli Serdang. Temperature control and humidity of white oyster mushrooms using Ardurino Uno R-3-based DHT 11 temperature sensor with 16x2 LCD display and HP Android. Controlling the temperature and humidity of white oyster mushrooms work automatically to help the mushroom farmers in controlling the temperature and humidity of white oyster mushroom kumbung .. If temperature > 300C and humidity $<650 \mathrm{C}$ sensors will read the temperature and humidity in the kumbung and regulate the movement of the water pump in automatic and turn the water nozzle in water spraying onto the kumbung section and baglog mushrooms. This tool works to help white oyster mushroom farmers in increasing their harvest production.
\end{abstract}

Keywords: Temperature Control and Humidity, Website

\begin{abstract}
Abstrak: Telah dilakukan Pengabdian Masyarakat bagi Usaha Mikro Jamur Tiram Puth'"Pengendalian suhu dan kelembaban, Benteng Hilir, Deli Serdang. Pengendalian suhu dan kelembaban jamur tiram putih menggunakan sensor suhu DHT 11 berbasis Ardurino Uno R-3 dengan tampilan LCD 16x2 dan HP Android. Pengontrolan suhu dan kelembaban kumbung jamur tiram putih bekerja secara otomatis membantu para petani jamur dalam mengendalikan suhu dan kelembaban kumbung jamur tiram putih.. Jika suhu $>30^{\circ} \mathrm{C}$ dan kelembaban $<65^{\circ} \mathrm{C}$ sensor akan membaca suhu dan kelembaban yang berada di kumbung dan mengatur pergerakkan pompa air secara otomatis dan menghidupkan nozzle air dalam penyemprotan air ke bahagian kumbung dan baglog jamur. Alat ini bekerja untuk membantu petani jamur tiram putih dalam peningkatan produksi panennya.
\end{abstract}

Kata Kunci : Pengendalian Suhu dan kelembaban, Website 
Jurdimas (Jurnal Pengabdian Kepada Masyarakat)

Vol. I No. 1, Januari 2018, hlm. 23 - 28

Available online at

http://jurnal.stmikroyal.ac.id/index.php/jurdimas
ISSN 2614-7912 (Print)

ISSN 2622-3813 (Online)

\section{PENDAHULUAN}

Beberapa penelitian yang telah dilakukan beberapa peneliti tentang pengendalian suhu dan kelembaban kumbung jamur jamur tiram diantaranya, Manunggal Ajie Putranto,2012, Pengendalian Suhu Ruang pada Budidaya Jamur Tiram dengan Karung Goni Basah, kelembaban relatifnya tidak berbeda nyata. Hasil panen jamur pada 75 baglogpada kondisi ruang yang didinginkan dengan karung goni basah adalah $23,5 \mathrm{~kg}$, sementara yang tidak didinginkan hasilnya $16,7 \mathrm{~kg}$.

Cyrilla Indri Parwati,2013, Kumbung Otomatis untuk Budidaya Jamur pada Industri Rumah Tangga, kelembaban pada media tanam jamur secara otomatis dengan menggunakan sensor DHT-11, sehingga budidaya jamur dapat diterapkan di rumah tangga, berdasarkan hasil pengujian didapatkan dengan satukumbung otomatis dengan ukuran tinggi $(120 \mathrm{~cm})$, panjang $(200 \mathrm{~cm})$ dan lebar $(50 \mathrm{~cm})$ mampu menghasilkan sekitar 3-4 kg jamur merang untuk setiap periode panen ( \pm setiap 10 hari) dan dalam satu bulan bisa terjadi 3 kali periode panen.

Terdapat juga beberapa IbM Pengembangan Bididaya Jamur adalah Mutiara Nugraheni, et,al 2013, "Teknologi Pengolahan Produk Berbasis Jamur di Kawasan Rawan Bencana Erupsi Merapi, bertujuan memberikan alternatif penanganan pasca panen jamur kuping dan jamur yang mampu menghasilkan produk yang dapat diterima konsumen; memberikan alternatif kepada konsumen produk berbahan dasar jamur dan mempunyai umur simpan yang lama dan membuka peluang pengembangan home industry berbasis agribisnis, metode kegiatan dilakukan dengan ceramah dan diskusi mengenai karakteristik jamur kuping dan jamur merang dan penanganan pasca panennya.

Setyowati, 2013, "IbM Pengembangan Agrobisnis Jamur di Kota Surakarta", Budidaya jamur dari milik Kelompok tani Jamur Alumni 149 sudah berdiri sejak tahun 2009 dan Usaha Tani Mandiri Ibu Surani berdiri satu tahun setelahnya (Tahun 2010). Dengan kumbung berukuran sekitar $100 \mathrm{~m}^{2}$, kedua usaha ini dapat terus berjalan.Kapasitas rumah jamur (kumbung) tersebut dapat memuat 6000 baglog, tetapi saat ini kumbung tersebut baru diisi oleh sekitar 1000-1200 baglog. Dari baglog yang ada, setiap hari usaha jamur Kelompok tani Jamur Alumni 149 dan Usaha Tani Mandiri Ibu Surani dapat menghasilkan jamur sekitar 12-15 kg dengan masa panen lebih kurang 4 bulan.

I Made Citra Wibawa, et, al, 2012,“ IbM Jamur", salah utama yang dihadapi oleh petani jamur itu adalah kurangnya penguasaan teknologi pasca panen jamur, teknologi pemilihan bibit unggul dan teknologi pemasaran. Kekurangan terhadap berbagai teknik tersebut mengatasi kekurangan petani jamur selama ini hasil pengabdian dalam bentuk IbM ini menunjukkan bahwa setelah pelatihan dilakukan, para petani jamur lebih terbuka wawasannya untuk memproduksi bibit jamur.

Pada kegiatan pengabdian pada masyarakat ini kami mengambil mitra dalam pengembangan budidaya jamur tiram diantaranya mitra I adalah "Bapak Sukanan Setiawan" adalah seorang petani perintis pengusaha mikro yang bergerak dibidang budidaya jamur tiram 
http://jurnal.stmikroyal.ac.id/index.php/jurdimas

putih.Beliau adalah seorang pekerja yang dulunya merupakan staff dari perusahaan pensiunan PT.TELKOM selama 24 tahun.Sejak tahun 2012 beliau mengambil langkah untuk berhenti atau pensiun dini dari pekerjaaannya berumur 48 tahun dan beralih profesi tertarik dalam hal pengembangan budidaya jamur tiram putih.

Beliau memulai usahanya mulai dari proses pembibitan hingga dalam proses hasil panen. Lokasi budidaya jamur didaerah Benteng Hilir No.19, Kecamatan Percut Sei Tuan Kota Deli Serdang dengan luas kumbung jamur yang dimiliki berukuran 7x11 meter, beratap tepas dan terpal dindingnya tepas.

\section{METODE}

\section{Metode Observasi dan Wawancara}

Pelaksana kegiatan mengadakan pengamatan di Benteng Hilir, Deli Serdang.Observasi dilakukan setelah memperoleh izin dari pihak-pihak terkait.Selain observasi, pelaksana juga melakukan wawancara dengan pihak Mitra Sumatera Kebun Jamur Bapak Sukanan Setiawan sebagi pemilik usaha Budi daya Jamur tiram putih guna menunjang pengumpulan data awal sebelum membuat usulan kegiatan program dan pelaksanaan program.I

Observasi juga dilakukan setelah pelatihan diadakan, untuk mengetahui manfaat hasil pelatihan.Pada observasi ini dicari data mengenai tingkat keberhasilan pembuatan Alat pencatat dan pengendalian suhu dan kelembaban digital dan otomatis dengan tampilan LCD16x2 dan tampilan dengan HP
Android dan pembuatan website hasil panen jamur tiram putih.

\section{Metode Penyuluhan dan Pelatihan}

Metode yang digunakan untuk mencapai tujuan yang telah dirumuskan di depan adalah metode diskusi dan praktek (learning by doing). Gabungan kedua metode tersebut diharapkan mampu meningkatkan pemahaman dan keterampilan khalayak berkaitan dengan teknik teknologi pengolahan pasca panen jamur .

Pelatihan yang dilakukan diantaranya adalah:

1. Pelatihan pembuatan alat pengontrolan suhu dan kelmbaban kumbung jamur tiram putih secara otomatis dengan tampilan LCD 16x2 dan HP Android bagi petani jamur tiram putih

2. Pelatihan Pembuatan Website untuk pemasaran hasil panen jamur tiram putih untuk peningkatan hasil pemasaran bagi petani jamur tiram putih.

\section{PEMBAHASAN}

Perancangan alat pengontrol suhu dan kelembaban ini bertujuan untuk memberikan kemudahan para petani jamur dalam pengontrolan suhu dan kelambaban secara otomatis yang akan menggerakkan pompa air dan nozzle untuk menyemprotkan air ke bahagian kumbung jamur dan baglog jamur.

\section{Pengujian Sistem dan Rangkaian}

Pengujian pada rangkaian sistem yang dilakukan adalah pengujian komponen pendukung dan program pengontrolan suhu dan kelembaban.Pengujian ini dilakukan 
http://jurnal.stmikroyal.ac.id/index.php/jurdimas

untuk dapat mengetahui suhu dan kelembaban kumbung jamur.

\section{Analisa Rangkaian}

Beberapa aspek yang perlu dikembangkan dalam pemahaman terhadap sistem merupakan satu kesatuan prosedur inti dari sistem tersebut.Sistem dikatakan lengkap bila dalam mencapai tujuan yang telah ditetapkan terjadi interaksi antara subsistem-subsistem yang ada. Pada sub bab berikut ini akan dijelaskan mengenai analisa perancangan rangkaian secara keseluruhan dan masingmasing yang mendukung tercapainya tujuan pembuatan alat ini.

1. Perlu dilakukannya penelitian selanjutnya pengontrolan suhu dan kelembaban dengan signifikan suhu dan kelembaban suhu dan kelembaban.

2. Pembuatan selanjutnya yaitu pembuatan otomatisasi listrik pengontrolan suhu dan kelembaban pada kumbung jamur

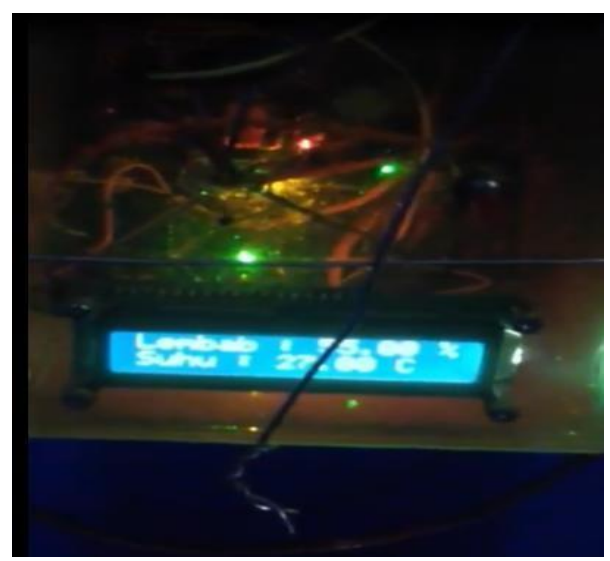

Gambar 4 Pengecekan Rangkaian Keseluruhan Bekerja dengan Baik

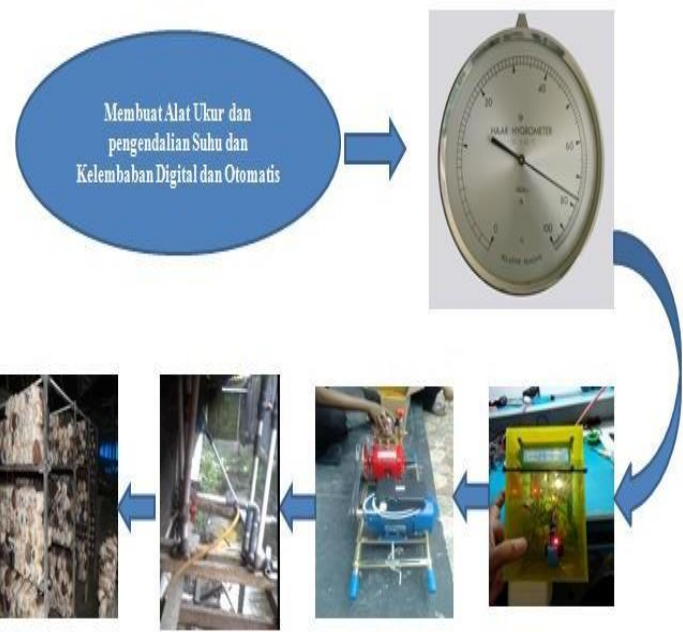

Gambar 5 Sistem Rangkaian Keseluruhan Proses Pemasaran

Pemasaran ini tidak harus menjualnya ke pasar saja, menjadi pemasok utama di bidang kuliner juga bagus. Atau kalau Anda ingin membuat produk olahan dari usaha budidaya jamur tiram Anda juga akan memberikan nilai lebih.

Hanya saja energi dan dana yang dikeluarkan di awal akan sangat besar. Ada banyak sekali pengusaha budidaya jamur tiram yang memanfaatkan peluang ini agar omset naik.Yang penting rajin promosi dan nimbrung diantara sesama pengusaha agar mendapatkan ide dan koneksi baru. Pelajari juga cara pengemasan jamur karena sayuran ini terkenal cepat layu. 
http://jurnal.stmikroyal.ac.id/index.php/jurdimas

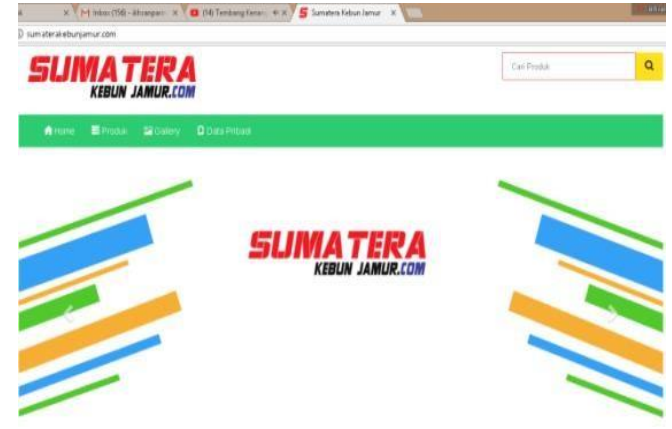

\section{Gambar 6 Pemasaran Hasil Panen Jamur Tiram}

\section{Cara Kerja Sistem}

Cara kerja sistem tersebut adalah sebagai berikut:

1. Arduino Uno berfungsi untuk mengontrol sistem untuk dapat bekerja sesuai dengan yang diharapkan.

2. Catu daya berfungsi untuk memberikan tegangan listrik keseluruh Hardware dari sistem.

3. Sensor DHT-11 berfungsi sebagai sensor suhu dan kelembaban.

4. Relay berfungsi sebagai penyambung dan pemutus tegangan listrik

5. Buzzer untuk alaram ketika sensor DHT 11 membaca suhu dan kelembaban $>30^{\circ} \mathrm{C}$

\section{SIMPULAN}

1. Pembuatan alat pengontrol suhu dan kelembaban jamur tiram putih sangat membantu para petani jamur dalam pengontrolan suhu dan kelembaban kumbung, baglog jamur tiram putih

2. Suhu kumbung jamur berkisar antara $27-30^{\circ} \mathrm{C}$ dengan kelembaban antara 65 $\%$
3. Alat pengontrolan suhu dan kumbung jamur bekerja secara otomatis dengan tampilan LCD16x2 dan HP Android

\section{DAFTAR PUSTAKA}

Alex, M.S. 2011. Meraih Sukses Dengan Budidaya Jamur Tiram, Jamur Merang, dan Jamur Kuping. Jakarta : Penebar Swadaya.

Cyrilla Indri Parwati, Catur Iswahyudi,2013, Kumbung Otomatis untuk Budidaya Jamur Pada IndustriRumah Tangga, Jurusan Teknik Industri Institut Sains \& Teknologi AKPRIND Yogyakarta. Simposium Nasional RAPI XII - 2013 FT UMS ISSN 1412-9612

Fandi Budiawan, Arman Jaya, ST. MT, Drs. Irianto, MT, Pengaturan Suhu Dan Kelembaban pada Miniatur Kumbung untuk Meningkatkan Produktifitas Jamur Tiram, Teknik Elektro Industri, Politeknik Elektronika Negeri Surabaya.

FuadAbdillah,NgubaidiAchmad,2015,Pen gembangan Jamur Tiram di Paguyuban Budidaya Jamur di Desa Milir Kecamatan Gubuk Kabupaten Grobogan.Fakultas Pendidikan Teknologi dan Kejuruan, IKIP Veteran Semarang. , Vol : XXII, No : 3, Vol : XXII, No : 3

I Made Sunarsa,Arif Restu Widodo,Susijanto Tri Rasmana,2010,Rancang Bangun Sistem Kontrol Pada Prototipe Kumbung Untuk Budidaya Jamur Merang Putih. Program Studi S1 
Jurdimas (Jurnal Pengabdian Kepada Masyarakat)

Vol. I No. 1, Januari 2018, hlm. 23 - 28

http://jurnal.stmikroyal.ac.id/index.php/jurdimas

Sistem Komputer, STIKOM Surabaya.SNASTI 2010, ICCS- 6, Manunggal Ajie Putrantodan Mad yamin,2012.Pengendalian Suhu Ruang pada Budidaya Jamur Tiramdengan Karung Goni Basah. Department of Mechanical and Biosystem Engineering, Faculty of Agricultural Engineering and Technology, Bogor Agricultural University.Vol. 26, No. 2, Oktober 2012

Susilawati., Raharjo, Budi. 2010.

Budidaya Jamur Tiram yang

Ramah Lingkungan. Report No 50.

STE Final. Palemban 